\title{
The Variations in Blood Pressure Values in Deadsea and Sea Level in Jordan are not Influenced by the Level of Angiotensin Ii
}

\author{
Kawther Faisal Amawi \\ Department of service requirement unit, Faculty of Science, Zarqa \\ University, Jordan \\ Mustafa Ahmad Al-Shehabat
}

Department of physiology, Faculty of Medicine, Jordanuniversity of Science and technology, Jordan

\section{Ali Alsarhan}

Department of pharmaceutical chemistry, Faculty of Pharmacy, University of Jadara, Jordan

doi: 10.19044/esj.2016.v12n36p141 URL:http://dx.doi.org/10.19044/esj.2016.v12n36p141

Abstract

Introduction: hypertension may be affected by environment. The variation of altitudes has been reported to play a role in hypertension. In Jordan, we have an environment rich in diversity as having areas in the sea level and others in the lowest depth in the world (the Dead Sea).

Objectives: to examine the impact of altitudes on the level of angioten II among study participants.

Methods and subjects: across sectional design was conducted. Two areas were included: the Dead Sea and the Sea level area, Jordan. The study sample included a total of 1000 participants of them 500 participants were included from each area. All participants were males, matched for age grouping, and they were apparently healthy. A working paper was made for each participant which included study variables such as blood pressure, weight, height, waist circumference, heart rate per minute, the level of angiotensin II, and packed cell volume (PCV). We analyzed data using SPSS version 20. All data were included and represented as mean and standard deviation. The relations between variables were computed using independent $T$ test. Significance was considered at alpha $<0.05$.

Study findings: there were no statistical differences between study groups for all variables except systolic blood pressure which its mean was $122.42 \pm 10.53$ $\mathrm{mmHg}$ in the area of Dead Sea and this was significantly higher than that of the Sea level $(118.07 \pm 11.64)(\mathrm{p}=0.001)$. The mean of blood pressure in the Dead Sea was $91.64 \pm 8.90 \mathrm{mmHg}$, and this was significantly higher than 
that of the Sea level $(89.84 \pm 8.72)(\mathrm{p}=0.001)$. The level of angiotensin II was $8.48 \pm 4.65 \mathrm{pg} / \mathrm{ml}$ in the Dead Sea area, and this was less than that of the Sea level $(11.21 \pm 6.05 \mathrm{pg} / \mathrm{ml})$. The difference in means for angiotensin II was not statistically significant.

Conclusion: the altitude differences in the study area affected, but not significantly, the level of angiotensin II and significantly the level of systolic blood pressure.

Keywords: Hypertension, altitude, angiotensin II, the Dead Se.

\section{Introduction}

Blood pressure means the force exerted by the blood against any unit area of the vessel wall (Urone, 1986); this force pushes blood to the different parts of the body to supply nutrients to the tissues and remove waste products away, i.e. to maintain homeostasis in all tissue fluids of the body for optimal survival and function of the cells (Guyton and Hall, 2006). Blood pressure develops normally in the left ventricle during the systolic part of the cardiac cycle (Ganong, 1997). Blood flow through the blood vessel depends mainly on the pressure gradient, wh\r4.ffv.vich is the force that pushes the blood through the vessel $(\mathrm{P}=\mathrm{F} \mathrm{X} \mathrm{R})$, whereas, $\mathrm{P}$ is pressure gradient, $\mathrm{F}$ is blood flow; $\mathrm{R}$ is the resistance (Guyton and Hall, 2006). Arterial blood pressure is regulated within a narrow range by baroreceptors to provide adequate perfusion of the tissues without causing damage to vascular system, particularly the arterial intima (Harvey and Champe, 2006). Mean arterial BP is a function of cardiac output $(\mathrm{CO})$ and total peripheral vascular resistance (TPR) (Berne and Levy, 2001) and, in mathematical terms, at constant CO, $\mathrm{BP}=\mathrm{CO} \mathrm{X}$ TPR . CO, in turn, is directly related to ECF volume and the volume of the venous return to the heart. Indeed, Borst and Borst-de Geus, 1963; Guyton and Coleman (1969), and Guyton, Jones and Coleman (1973)observed that acute plasma volume expansion elevates the BP by increasing CO. Most patients with chronically elevated BP have a relatively normal CO and significantly elevated TPR(Cowley, 1992; Williams and Wilkins, 2002). According to Guyton, the tissue over-perfusion is an abnormal condition, and TPR, therefore, increases until tissue perfusion returns to normal. One explanation is that this autoregulation is controlled by the metabolic demands of the tissues (Borst and Borst-de Geus, 1963; Guyton, Jones and Coleman, 1973; Williams and Wilkins, 2002).

Angiotensin I is converted to angiotensin II through removal of two terminal residues by the enzyme Angiotensin-converting enzyme (ACE), which is found predominantly in the capillaries of the lungs (Basso and Terragno, 2001). ACE is actually found all over the body, but it has its highest 
density in the lung. Angiotensin II acts as an endocrine, autocrine/ paracrine, and intracrine hormone (Devlin, 2006).

ACE is a target for inactivation by ACE inhibitor drugs, which decrease the rate of angiotensin II production. Angiotensin II increases blood pressure by stimulating the Gq protein in vascular smooth muscle cells (which in turn activates contraction by an IP3-dependent mechanism). ACE inhibitor drugs are major drugs against hypertension.

Angiotensin II is degraded to angiotensin III by angiotensinases that are located in red blood cells and the vascular beds of most tissues. It has a half-life in circulation of around 30 seconds, while in tissues; it may be as long as 15-30 minutes (Skurk, Lee, Hauner, 2001).

\section{Study objectives}

The main objective of the current study is to examine the impact of altitudes on the level of angiotensin II among study participants.

\section{Methods and subjects \\ Study design}

Cross sectional design was conducted.

\section{Study setting}

The present study was conducted in two areas: the Dead Sea and the Sea level area, Jordan.

\section{Study sample}

The study sample included a total of 1000 participants of them 500 participants were included from each area. All participants were males, matched for age grouping, and they were apparently healthy.

\section{Data collection}

A working paper was made for each participant which included study variables such as blood pressure, weight, height, waist circumference, heart rate per minute, the level of angiotensin II, and packed cell volume (PCV).

\section{Study procedure}

\section{Blood pressure measurements}

Blood pressure was taken for 500 subjects in each target area; it was taken from the right arm of the subject, in a sitting position and after resting for 5 minutes. Blood pressure was taken by sphygmomanometer with a stethoscope. 


\section{Measurement of height}

Height was measured for our subjects by using 2 metric scaled rulers fixed to the wall of the room. It was in centimeters.

\section{Weight measurement}

Weight was measured for all subjects using a well calibrated scale.

\section{Waist circumference measurement}

Waist circumference was measured by a manual metric scale in centimeters.

\section{Heart rate measurement}

Radial pulse from the left hand for full minute, the subjects were at rest.

\section{Angiotensin II measurement}

We used enzyme immunoassay (EIA) to measure the level of angiotensin II.

\section{Data analysis}

We analyzed data using SPSS version 20. All data were included and represented as mean and standard deviation. The relations between variables were computed using independent $\mathrm{T}$ test. Significance was considered at alpha $<0.05$.

\section{Results}

Comparison between the Means and Standard Deviations of Blood Pressure and other Variables in the Dead Sea and Sea Level Areas

We measure different variables to examine the impacts of altitudes on the health of persons. As it can be illustrated in table 1, participants in both groups had similar age groups (17.60 \pm 0.51 years), and no significant variations were observed among participants between Dead Sea and sea level areas $(\mathrm{P}>0.05)$.

Table 1 also indicated that no significant differences in the means of weight, height, BMI, and waist circumferences were observed between Dead sea and sea level groups. The mean level of systolic blood pressure was $122.42 \pm 10.53 \mathrm{~mm} \mathrm{Hg}$ among subjects in the Dead Sea and this was significantly higher than the mean level of subjects in the area of Sea level $(\mathrm{p}=0.001)$. There was no statistically significant differences in the mean level of both groups for diastolic blood pressure. Participants from the Dead Sea had a significantly higher mean of mean blood pressure $(91.64 \pm 8.90 \mathrm{~mm} \mathrm{Hg})$ than those in the area of the Sea level $(89.84 \pm 8.72)(\mathrm{p}=0.001)$. 
Table 1:Comparison between the Means and Standard Deviations of Blood Pressure and other Variables in the Dead Sea and Sea Level Areas

\begin{tabular}{|c|c|c|c|}
\cline { 2 - 4 } \multicolumn{1}{c|}{} & Dead Sea & Sea level & \\
\hline Variables & Mean \pm std & Mean \pm std & P value \\
\hline Age & $17.60 \pm 0.51$ & $17.60 \pm 0.51$ & NS \\
\hline Weight/kg & $67.31 \pm 10.77$ & $67.69 \pm 8.70$ & NS \\
\hline Height/cm & $169.29 \pm 6.52$ & $170.50 \pm 5.85$ & NS \\
\hline BMI & $23.45 \pm 3.27$ & $23.26 \pm 2.57$ & NS \\
\hline Waist cir./c & $76.37 \pm 10.26$ & $76.38 \pm 6.00$ & NS \\
\hline SBP/mmHg & $122.42 \pm 10.53$ & $118.07 \pm 11.64$ & $0.001^{*}$ \\
\hline $\mathrm{DBP} / \mathrm{mmHg}$ & $76.31 \pm 9.14$ & $75.74 \pm 8.48$ & NS \\
\hline $\mathrm{MBP} / \mathrm{mmHg}$ & $91.64 \pm 8.90$ & $89.84 \pm 8.72$ & $0.001^{*}$ \\
\hline $\mathrm{Pulse} / \mathrm{minute}$ & $79.74 \pm 6.17$ & $79.07 \pm 6.46$ & $\mathrm{NS}$ \\
\hline $\mathrm{PCV}$ & $42.17 \pm 3.18$ & $41.50 \pm 3.27$ & $\mathrm{NS}$ \\
\hline
\end{tabular}

NS: Not Significant

\section{The concentration of Angiotensin II Concentration in Dead Sea and Sea} Areas

The mean level of Angiotensin II was $8.84 \pm 4.65 \mathrm{pg} / \mathrm{ml}$ among participants in the Dead Sea, while it was $11.21 \pm 6.05 \mathrm{pg} / \mathrm{ml}$. The difference in the concentration of angiotensin II between the study groups was not statistically significant ( $>0.05)$ (table 2$)$.

Table 2: Comparison between Angiotensin II Concentration in Dead Sea and Sea Areas

\begin{tabular}{|c|c|c|c|c|}
\hline Target Area & $\begin{array}{c}\text { Mean } \pm \text { SD } \\
(\mathrm{pg} / \mathrm{ml})\end{array}$ & Target Area & $\begin{array}{c}\text { Mean } \pm \text { SD } \\
(\mathrm{pg} / \mathrm{ml})\end{array}$ & P value \\
\hline Dead Sea & $8.84 \pm 4.65$ & Sea level & $11.21 \pm 6.05$ & NS \\
\hline
\end{tabular}

NS: Not Significant

\section{Discussion}

Blood pressure is the main force for the hemodynamics that keeps continuous blood flow for all the body tissues which is essential for homeostasis. It is well known that blood pressure is regulated by two factors: first factor is the peripheral resistance which mainly depends on the elasticity of arterial system, mainly the arterioles, which determines the radius of these arteries and the influence of sympathetic activity through the baroreceptors during transient change of blood pressure. Also the level of the angiotensin hormone significantly can change the diameter of arterioles i.e. the peripheral resistance.

The second factor which regulates blood pressure is the blood volume which is mainly regulated by the level of rennin-angiotensin system that starts mainly from the kidney. So any condition that decreases or increases the level 
of blood pressure will be antagonized by changing the level of angiotensin. The first line to change the radius is the vasoconstriction. It is the presence of oxygen that can cause vasoconstriction and hypoxia causes vasodilatation and this oxygen availability is different at different levels of altitude i.e. hypoxia at high altitude and high oxygen concentration at low altitude.

A study entitled by the effect of altitude on blood pressure in the Assir province of Saudi Arabia which has been carried out by the department of physiology, King Saud University has measured normal blood pressure, body weight, height, and packed cell volume (PCV) in healthy, normal Saudi adult males who were born and were living permanently at high altitude $(3150 \mathrm{~m})$ in southern Saudi Arabia (Habib et al., 1995). These values have been compared with those obtained from healthy, normal Saudi Arab adult males born and living permanently at low altitude (500 $\mathrm{m}$ above sea level). Results have showed that residents at high altitude have higher PCV than their lowland counterparts. Their mean body mass index (BMI) values have not been significantly different. Small but significant increase in systolic blood pressure (SBP) and diastolic blood pressure (DBP) have been observed in high-altitude residents (112 and $75 \mathrm{~mm} \mathrm{Hg}$, respectively) when compared with low altitude residents (109 and $71 \mathrm{~mm} \mathrm{Hg}$, respectively) ( $\mathrm{p}<0.001$ for both SBP and DBP).

Another study which has been carried out by four universities in Italy in a shared work (Veglio et al., 1999) so as to evaluate the effects of exposure to a moderate altitude $(2950 \mathrm{~m})$ on heart rate $(\mathrm{HR})$, blood pressure $(\mathrm{BP})$ profile, and cardiovascular autonomic function, and their correlation with hemoglobin oxygen saturation $(\mathrm{HbO} 2 \mathrm{~S})$, in untrained subjects with an age range between 6 and 83 years. In this study twenty-seven healthy normotensive subjects (age range 6-83 years; 8 children, 9 adults, and 10 elderly subjects) underwent a battery of noninvasive cardiovascular reflex tests and 24-h ambulatory BP monitoring. Corrected QT interval was also calculated. $\mathrm{HbO}_{2} \mathrm{~S}$ has been measured with a transcutaneous oxymeter. All measurements have been performed at about $200 \mathrm{~m}$ and repeated at $2950 \mathrm{~m}$. 24-h HR and systolic/diastolic BP mean values increased at $2950 \mathrm{~m}$ in children (\% change respectively: $6.4 \pm 6.4, \mathrm{p}<0.05 ; 6.5 \pm 4.0 / 13.5 \pm 6.9, \mathrm{p}<0.05$ ), adults $(4.9 \pm 8.1, \mathrm{NS} ; 6.0 \pm 5.1 / 8.1 \pm 5.8, \mathrm{p}<0.05)$, and elderly subjects $(7.2 \pm 4.8, \mathrm{p}<0.05$; $5.1 \pm 2.3 / 2.8 \pm 4.1, \mathrm{p}<0.05$ for systolic BP only). Standard deviation of BP mean values has increased during night-time in the adult group $(\mathrm{p}<0.05)$. All subjects have scored normal cardiovascular test results and no differences have been observed after exposure to $2950 \mathrm{~m}$, at both 1 hour and 24 hours from arrival. After exposure to high altitude, $\mathrm{HbO}_{2} \mathrm{~S}$ has decreased significantly in the three groups, both on arrival and after 24 hours. No correlation has been found between changes in $\mathrm{HbO}_{2} \mathrm{~S}$ and $\mathrm{BP} / \mathrm{HR}$ responses, and cardiovascular test results. In conclusion, exposure to moderate altitudes, easily and often 
reached by the general population, causes a small but significant increase in $\mathrm{BP}$ and HR in healthy untrained subjects of a wide age range (6-83 years).

It is worth mentioning that a clinical study which has been carried out in the Dead Sea area- Israel by Ben Gurion University (Paran, Neuman,Sukenik, 1998) has shown that seventy two elderly patients suffering from rheumatoid arthritis and osteoarthritis, both hypertensive and normotensive patients have demonstrated a decrease in BP during their stay in the Dead Sea area. This decrease has been most apparent on the $8^{\text {th }}$ day of stay and has been moderated toward the $12^{\text {th }}$ day of stay.

According to our knowledge this study is the only original physiological study to examine the effect of low altitude on blood pressure through which blood pressure, PCV, and angiotensin II were measured as part of a comprehensive study included sea level and high altitude level.

So, as to clarify the effect of altitude on blood pressure, angiotensin II has been measured. Other variables that affect blood pressure have been also measured so as to exclude their effect on it; these variables are BMI, waist circumference, pulse rate, gender and age. All these variables except pulse rate had no effect on the results of our study since our target subjects are healthy slim males and the same age, their values are insignificant $(p$ value $>0.05)$.

Our results, however, are compatible with those of a study which has been performed in Abha, Saudi Arabia by the department of physiology in King Saud University in which they have tested the effect of altitude on blood pressure in the Assir province of Saudi Arabia (Habib et al., 1995) and it is also comparable with most of the international studies which have been carried out to clarify the effect of high altitude on blood pressure. The explanation of higher blood pressure in high altitude is that both the direct and indirect effects of the hypoxia are likely to contribute to causing the increase in sympathetic activity at high altitude. Hypoxia acts on vascular smooth muscle in the systemic circulation causing relaxation and therefore hypotension. This, in turn, will lead to baroreceptor-mediated sympathetic excitation. An additional mechanism for exciting sympathetic activity may also arise through stimulation of pulmonary arterial baroreceptors.

\section{References:}

1. Ardaillou R (1997). Active fragments of angiotensin II: enzymatic pathways of synthesis and biological effects. Curr Opin Nephrol Hypertens. 6: 28-34.

2. Basso N and Terragno NA (2001). History about the discovery of the renin-angiotensin system. Hypertension 38 (6): 1246-9.

3. Berne RM and Levy MN (2001). Cardiovascular Physiology (8th edition). St. Louis, MO: Mosby. 
4. Berry C, Touyz R, Dominiczak AF, et al (2002). Angiotensin receptors: signaling, vascular pathophysiology, and interactions with ceramide. Am. J. Physiol. Heart Circ. Physiol., 281 (6): H2337-65.

5. Borst JGG and Borst-de Geus A (1963). Hypertension explained by Starling's theory of circulatory homoeostasis. Lancet 1: 677-682.

6. Cowley AW Jr (1992). Long-term regulation of arterial blood pressure. Physiol Rev, 72, 231-300.

7. Ganong, W (1997). Review of Medical Physiology. New Jersey: Simon \& Schuster Company.

8. Guyton AC and Coleman TG (1969). Quantitative analysis of the pathophysiology of hypertension. Circ Res 24, Suppl 5: 1-19.

9. Guyton AC, Jones CE, and Coleman TG (1973). Circulatory Physiology: Cardiac Output and Its Regulation. Philadelphia, PA: Saunders.

10. Guyton and Hall (2006). Textbook of Medical Physiology. Pennsylvania: Elsevier Saunders.

11. Hall JE (2003). Historical perspective of the renin-angiotensin system. MolBiotechnol 39.

12. Harvey and Champe (2006). Pharmacology. Donnelley. USA.

13. Johnson PC (1986). Autoregulation of blood flow. Circ Res 59: 483495.

14. Kaplan NM. (2002) Kaplan's Clinical Hypertension, Philadelphia, PA: Lippincott Williams and Wilkins.

15. Lees KR, MacFadyen RJ, Doig JK, Reid JL. Al Guazzi MD, De Cesare N, Fiorentini C, Galli C, Moruzzi P, Tamborini G (1993). The lesser circulation in patients with systemic hypertension. Circulation, 75: I56-I62.

16. Massimo Veglio' Simona Maule, Giovanni Cametti, Annalisa Cogo, Livio Lussiana, Giuseppe Madrigale,Oriana Pecchio

Cardiovascular responses to altitude. CommissioneCentraleMedica Club AlpinoItaliano, Italy.

17. Mohammad El Habib M. Khalid; Festus K. Adzaku (1995). The effect of altitude on blood pressure in the Assir Province of Saudi Arabia. Wilderness and Environmental Medicine, 6 (4): 401-406. 
18. Paran E, Neuman L, Sukenik S (1998). Soroka medical center: Faculty of health science. Ben Gurion University of the Negev. Beer Sheva: Soroka medical center, Isreail.journal of hypertension, 12. 551555.

19. Paul Peter Urone (1986).. Physics with health science applications. Canada. Library of Congress Cataloging in Publication Data.

20. Royal Geographical Center (2009) Monitoring of the Dead Sea. Israel Marine Data Center ISRAMAR .

21. Skurk T, Lee YM, Hauner H (2001). Angiotensin II and its metabolites stimulate PAI-1 protein release from human adipocytes in primary culture". Hypertension 37 (5): 1336-40.

22. Suzan Oparil and Michael A (2004). Webester. Hypertension. Elsevier Saunders. Pennsylvania.

23. Thomas M. Devlin (2006). Role of angiotensin in the extravascular system. Journal of human hypertension, 7 (2): 7-12.

24. WHO World Health (1996). Statistics Annual 1995. World Health Organization, Geneva.. 